\title{
Biosynthesis of Somatostatin in Canine Fundic D Cells
}

\author{
Tsutomu Chiba, Jung Park, and Tadataka Yamada \\ Department of Internal Medicine, The University of Michigan Medical School, Ann Arbor, Michigan 48109-0362
}

\begin{abstract}
The observation that virtually all of the somatostatin-like immunoreactivity in the stomach consists of somatostatin-14 (S14), to the exclusion of somatostatin-28 (S28), suggests a unique pattern of prosomatostatin posttranslational processing. In order to examine the mechanisms by which S14 is produced from its precursor in the stomach, we investigated the biosynthesis of somatostatin in isolated canine fundic $D$ cells. D cells pulse-labeled with ${ }^{35}$ S $]$ cysteine revealed a cycloheximide inhibitable time-dependent incorporation of radioactivity into S14. A small fraction of radioactivity was incorporated into S28 but not into larger precursors. However, when the cells were incubated with monensin $(1 \mu \mathrm{M})$, incorporation of radioactivity into a presumed somatostatin precursor was noted. Upon transfer of ${ }^{35}$ S $]$ cysteine prelabeled cells to radioactivity-free medium, no conversion of $S 28$ to $S 14$ could be detected and the decrease of labeled S14 in cells correlated with a complimentary increase in the culture medium. Exogenous somatostatin inhibited somatostatin biosynthesis in a fashion that could be blocked by pertussis toxin pretreatment. Stimulation of prelabeled D cells with tetradecanoyl phorbol 13-acetate $\left(10^{-7} \mathrm{M}\right)$ or forskolin $\left(10^{-4} \mathrm{M}\right)$ for $2 \mathrm{~h}$ resulted in release of 41 and $33 \%$ of the newly synthesized radioactive S14, respectively, while only 9 and $6 \%$ of the total cell content of radioimmunoassayable somatostatin was secreted. These data suggest that: (a) somatostatin is synthesized in fundic D cells primarily as S14, (b) S14 is produced by rapid processing of a larger precursor but there is little, if any, conversion of S28 to $\mathrm{S14}$, (c) somatostatin biosynthesis is autoregulated, and (d) newly synthesized S14 is preferentially released from D cells in response to stimulation.
\end{abstract}

\section{Introduction}

Somatostatin, a tetradecapeptide initially isolated from the hypothalamus, is also found in D cells of the gastric antrum and fundus where it is thought to exert an inhibitory action on gastric acid secretion and gastrin release (1). Although various molecular forms of somatostatin have been described in other tissues, the tetradecapeptide (somatostatin-14 [S14]) ${ }^{1}$ predomi-

Address all correspondence to Dr. Tadataka Yamada, 3912 Taubman Center, University of Michigan Medical Center, Ann Arbor, MI 48109-0362.

Received for publication 14 May 1987 and in revised form 8 September 1987.

1. Abbreviations used in this paper: EBSS, Earle's balanced salt solution; S14, somatostatin-14; S28, somatostatin-28; SLI, somatostatinlike immunoreactivity; TFA, trifluoroacetic acid; TPA, tetradecanoyl phorbol 13-acetate.

J. Clin. Invest.

(c) The American Society for Clinical Investigation, Inc.

0021-9738/88/02/0282/06 \$2.00

Volume 81, February 1988, 282-287 nates in the stomach with minute amounts of octacosapeptide (somatostatin-28 [S28]) being present as the only other detectable form (2-5). Since S14 comprises the carboxyl terminal 14 amino acids of S28, S28 is presumed to be the precursor of S14. Identification in tissues of the amino-terminal fragment that might result from endoproteolytic cleavage of S28 during the formation of S14 (S28 $\left.{ }_{1-12}\right)$ supports such an hypothesis (6). However, identification of peptides with carboxyl terminal S28 ${ }_{1-12}$ immunoreactivity that are clearly much larger than S28 ${ }_{1-12}$ suggest that S28 per se may not be the sole precursor of S14 (7). Indeed in the central nervous system biosynthesis of S14 and S28 from larger precursors has been demonstrated without evidence for direct conversion of S28 to S14 (8-10). We have undertaken the present studies to explore the mechanisms of somatostatin posttranslational processing in the stomach with special reference to the precursor-product relationship between S28 and S14. The availability of isolated fundic $D$ cells for these studies $(5,11)$ provided a unique opportunity to examine S14 biosynthesis in a system virtually devoid of S28.

\section{Methods}

Chemicals. Collagenase (type I), EDTA, dithiodipyridine, canavanine, thialysine, bovine insulin, hydrocortisone, gentamicin sulfate, L-cysteine, cycloheximide, monensin, Trasylol, antipain, leupeptin, and 12-O-tetradecanoyl phorbol 13-acetate (TPA) were purchased from Sigma Chemical Co. (St. Louis, MO). Forskolin, calcium ionophore A23187, and Hepes were products of Calbiochem-Behring Corp. La Jolla, CA). Earle's balanced salt solution (EBSS), Ham's F12-Dulbecco's modified Eagle's (50:50 vol/vol) culture media, and cysteinedeficient Ham's F12 Dulbecco's modified Eagle's culture media were obtained from Irvine Scientific (Santa Ana, CA). Pertussis toxin was supplied by List Biological Laboratories (Campbell, CA) and gelatin was purchased from Difco Laboratories Inc. (Detroit, MI). Synthetic S14, Tyr ${ }^{1}$-S14 and S28 were obtained from Peninsula Laboratories Inc. (Belmont, CA). Biogel P-6 and Affi-gel 10 were products of Bio-Rad Laboratories (Richmond, CA). Trifluoroacetic acid (TFA) was purchased from Pierce Chemical Co. (Rockford, IL) and acetonitrile was from Fisher Scientific Co., Allied Corp. (Fair Lawn, NJ). Goat antirabbit gamma globulin was obtained from Research Products International Corp. (Malvern, PA). $\left[{ }^{35} \mathrm{~S}\right]$ Cysteine $(970-1,020 \mathrm{Ci} / \mathrm{mmol}$ ) was a product of New England Nuclear (Boston, MA) and $\left[{ }^{3} \mathrm{H}\right]$ proline (L-[2,3,4,5,- $\left.{ }^{3} \mathrm{H}\right]$ proline, $\left.100-120 \mathrm{Ci} / \mathrm{mmol}\right)$ was from Amersham Corp. (Arlington Heights, IL).

Cell isolation and culture. Cells were dispersed from freshly obtained adult canine gastric mucosa as reported previously $(5,11)$. Briefly, the stomachs were divided into fundic and antral segments, and the fundic mucosa was bluntly separated from the submucosa. Mucosal fragments were incubated sequentially in collagenase $\mathbf{0 . 3 5}$ $\mathrm{mg} / \mathrm{ml})$ and EDTA $(1 \mathrm{mM})$, and the dispersed cells were separated by counterflow elutriation using a JE-6B elutriation system (Beckman Instruments, Inc., Fullerton, CA). The somatostatin cell fractions were collected and then layered at a density of $2.5-3.5 \times 10^{6}$ cells/well onto a bed of collagen (rat tail) in a 24-mm multiwell tissue culture plate in 1 ml of Ham's F12 Dulbecco's modified Eagle's (50:50) medium containing $10 \%$ dialyzed dog serum, insulin $(8 \mu \mathrm{g} / \mathrm{ml})$, hydrocortisone (1 $\mu \mathrm{g} / \mathrm{ml})$, and gentamicin $(100 \mu \mathrm{g} / \mathrm{ml})$. Deletion of insulin or hydrocor- 
tisone from the medium did not alter the results of the biosynthetic experiments.

Biosynthesis experiments. After an overnight stabilization of the cultures at $37^{\circ} \mathrm{C}$ in the presence of $95 \%$ air $/ 5 \% \mathrm{CO}_{2}$, the medium was replaced with cysteine-deficient culture medium containing $200 \mathrm{KIU} /$ $\mathrm{ml}$ Trasylol and $\left[{ }^{35} \mathrm{~S}\right]$ cysteine $(50-100 \mu \mathrm{Ci} /$ well $)$ in which the cells were cultured for an additional $4 \mathrm{~h}$. In some studies, the incubations were performed in the presence of cycloheximide $(0.3 \mathrm{mM})$; protease inhibitors such as antipain, dithiodipyridine, and leupeptin; and free cysteine $(40 \mu \mathrm{g} / \mathrm{ml})$ or monensin $(1 \mu \mathrm{M})$. Experiments were also performed in which arginine and lysine in the culture medium were substituted with canavanine and thialysine. In separate pulse-chase experiments, the medium with $\left[{ }^{35} \mathrm{~S}\right]$ cysteine was discarded and the cells were incubated in culture media containing nonradioactive cysteine, after washing three times with the same buffer. Similar "pulse-chase" experiments were also performed using $\left[{ }^{3} \mathrm{H}\right]$ proline $(50-100 \mu \mathrm{Ci} /$ well $)$ in the culture media in place of $\left[{ }^{35} \mathrm{~S}\right]$ cysteine.

In a separate series of studies, the effect of exogenously administered somatostatin on the biosynthesis of somatostatin was investigated. For these experiments, fundic $D$ cells were pulse labeled in the presence or absence of somatostatin $\left(10^{-7} \mathrm{M}\right)$ for $4 \mathrm{~h}$. Some cells were preincubated with $200 \mathrm{ng} / \mathrm{ml}$ of pertussis toxin for $4 \mathrm{~h}$ before these experiments.

Characterization of biosynthetic products. After completion of pulse-labeling or pulse-chase incubations, the media from the cultures were discarded and the cells were washed three times with EBSS. Cells from three wells were combined into one tube, and extracted by boiling for $15 \mathrm{~min}$ in $3 \%$ acetic acid. The extracts were then applied to affinity chromatography on Affi-gel beads linked to somatostatin antisera 7812 as described previously (8). This antibody was generated in rabbits against synthetic somatostatin tetradecapeptide and was directed at the central portion (positions 4-13) of the somatostatin molecule. It has $90 \%$ crossreactivity with S28 and has been demonstrated to recognize larger forms of somatostatin. The binding capacity of the affinity beads exceeded $1 \mathrm{nmol}$ of synthetic somatostatin per $\mathrm{ml}$. The columns were washed repeatedly with distilled water followed by $0.1 \mathrm{M}$ ammonium acetate, $\mathrm{pH}$ 5.0, until no additional radioactivity was removed, and then the remaining radioactivity was eluted with $3 \mathrm{ml}$ of $2 \%$ TFA. Aliquots of the affinity eluates were rotary evaporated, reconstituted with $0.1 \mathrm{M}$ ammonium acetate, $\mathrm{pH} 5$, then applied to a Biogel P-6 column $(1 \times 60 \mathrm{~cm})$ and eluted with $0.1 \mathrm{M}$ ammonium acetate, $\mathrm{pH} 5$, in the presence of $8 \mathrm{M}$ urea. Radioactivity in the eluted fractions $(0.6$ $\mathrm{ml}$ ) was counted in a liquid scintillation counter. The remainder of the affinity eluates were diluted with $0.5 \%$ TFA and applied to $\mu$ Bondapak C18 columns $(0.8 \times 10 \mathrm{~cm}$; Waters Associates, Millipore Corp., Milford, MA) in a 100A high pressure liquid chromatography (HPLC) system (Beckman Instruments, Inc.). The columns were eluted isocratically at a flow rate of $2 \mathrm{ml} / \mathrm{min}$ with $24 \%$ acetonitrile in $0.1 \%$ TFA. The elution profile of radioactivity in the $0.5-\mathrm{ml}$ fractions was compared against the elution profile of somatostatin-like immunoreactivity (SLI) obtained when synthetic S14 and S28 were applied under identical circumstances. Recovery of the applied radioactivity averaged $94 \%$. The specificity of the radioactive peaks that coeluted with S14 and S28 on Biogel P-6 chromatography and HPLC was validated as follows:

(a) Aliquots of column eluates were incubated for $24 \mathrm{~h}$ at $4^{\circ} \mathrm{C}$ with $0.1 \mathrm{ml}$ of somatostatin antibody RA-823 at a 1:100 dilution followed by a second $24-\mathrm{h}$ incubation with $0.1 \mathrm{ml}$ of goat anti-rabbit gamma globulin $(25 \mathrm{U} / \mathrm{ml})$ in a final volume of $1 \mathrm{ml}$ of $0.035 \mathrm{M}$ sodium phosphate (pH 7.4) containing $0.1 \mathrm{M} \mathrm{NaCl}$ and $2 \%$ (vol/vol) plasmanate. Antibody RA-823 was raised against synthetic $S 14$ in rabbits and recognized S14 and S28 equally well (12). After centrifugation, less than $10 \%$ of radioactivity was recovered in the supernatants of the fractions corresponding to S14 and S28.

(b) Samples of peaks corresponding to S14 and S28 on Biogel P-6 chromatography were examined by HPLC and comparable fractions following HPLC were reexamined by chromatography on Biogel P-6.
In each case the radioactivity retained the elution characteristics of $\mathrm{S} 14$ or $\mathbf{S 2 8}$ on the two columns.

Release studies. The release of newly synthesized somatostatin was compared with that of total cellular somatostatin stores. After a 4-h incubation in medium containing $\left[{ }^{35} \mathrm{~S}\right]$ cysteine, the cells were washed three times with EBSS then incubated in EBSS supplemented with $0.1 \%$ gelatin and $15 \mathrm{mM}$ Hepes with or without added TPA $\left(10^{-7} \mathrm{M}\right)$ or forskolin $\left(10^{-4} \mathrm{M}\right)$ for $2 \mathrm{~h}$. Then the media were removed, cells were extracted as described above, and SLI both in the media and the cells was measured by radioimmunoassay utilizing antibody SL-7 as described previously $(13,14)$. Aliquots from the same samples were used for quantifying newly synthesized, radiolabeled somatostatin by affinity chromatography followed by HPLC.

Statistical analysis. Statistical comparisons were performed using Student's $t$ test, with paired analysis when appropriate.

\section{Results}

As shown in Fig. 1, D cells incubated in the presence of $\left[{ }^{35} \mathrm{~S}\right]$ cysteine incorporated radioactivity into material adsorbable with a somatostatin affinity column. At $30 \mathrm{~min}$ of incu-
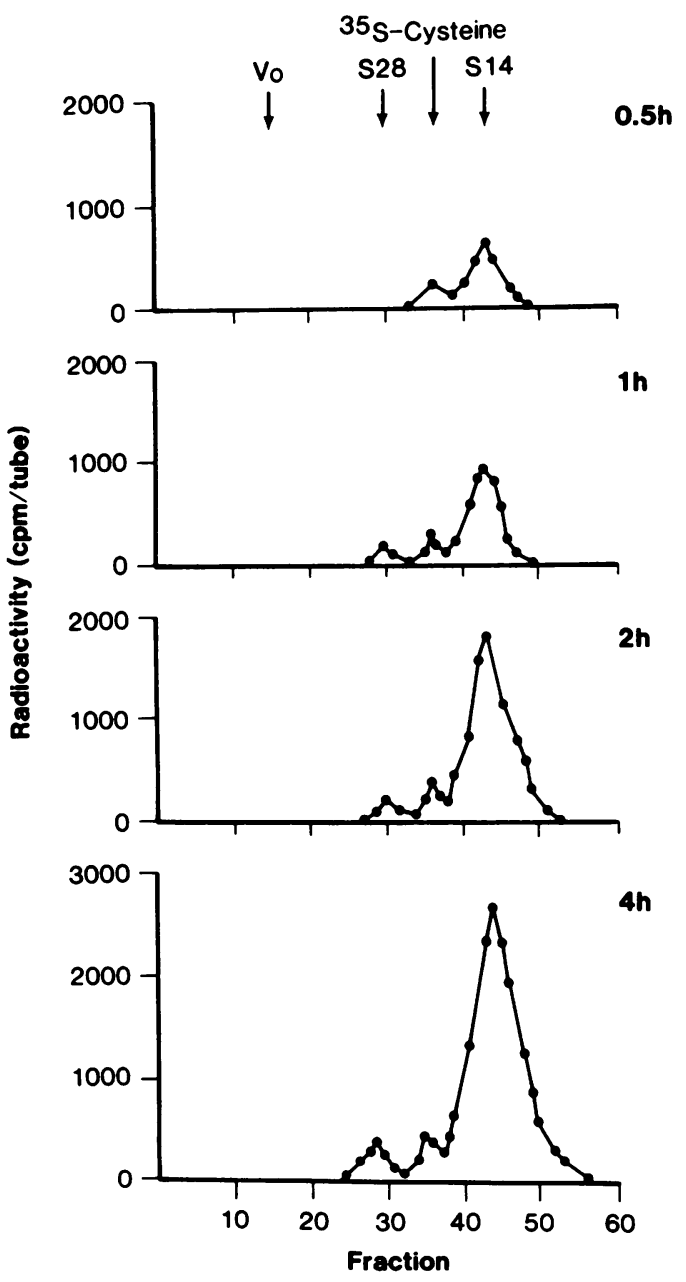

Figure 1. Chromatographic elution pattern of affinity-adsorbable radioactivity in $\mathrm{D}$ cells pulse labeled with $\left[{ }^{35} \mathrm{~S}\right]$ cysteine. The affinity eluate was applied to a Biogel P-6 column $(1 \times 60 \mathrm{~cm})$ and eluted with $0.1 \mathrm{M}$ ammonium acetate, $\mathrm{pH} 5.0$. Radioactivity in aliquots of eluted $0.6-\mathrm{ml}$ fractions was quantified in a liquid scintillation counter. The column was calibrated by denoting the elution fractions for blue dextran (Vo), S14, S28, and free $\left[{ }^{35}\right.$ S $]$ cysteine. 
bation, only a small radioactive peak corresponding to $\mathrm{S} 14$ on gel filtration was observed. This peak was preceded by a smaller peak which appeared to be nonspecifically adsorbed free $\left[{ }^{35} \mathrm{~S}\right]$ cysteine on the basis of its elution profile. Later, however, a third peak corresponding to $\mathbf{S} 28$ was also detected. The peaks corresponding to $\mathbf{S} 28$ and S14 could be immunoprecipitated completely with a second antisomatostatin antibody while the peak coeluting with $\left[{ }^{35} S\right]$ cysteine could not. To confirm the biochemical characteristics of the newly synthesized SLI, aliquots of the affinity eluates were also applied to HPLC and, again, two primary peaks coeluting with S14 and S28 were obtained, both of which could also be immunoprecipitated with a second antisomatostatin antibody (Fig. 2). Contaminating free $\left[{ }^{35} \mathrm{~S}\right]$ cysteine was eluted in the void volume in this system. Radioactivity associated with both S14 and S28 gradually increased over time, although the peak for S14 was much larger than that for $\mathrm{S} 28$ at any point. The actual percentages of radiolabeled S28 in the total radiolabeled pool of somatostatin in a typical experiment were $0,7.1,5.7$, and $6.1 \%$ as determined by gel filtration and 5.7, 6.0, 5.2, and $5.2 \%$ by HPLC at the $0.5,1,2$, and $4 \mathrm{~h}$ time point, respectively. When the radioactivities corresponding to S14 and S28 by HPLC were combined, synthesis of somatostatin increased in virtually linear fashion for up to $6 \mathrm{~h}$ (Fig. 3). In contrast, when the protein synthesis inhibitor cycloheximide was added to the incubation media the synthesis of somatostatin was almost completely blocked. The incorporation of $\left[{ }^{35} \mathrm{~S}\right]$ cysteine into SLI was also inhibited by addition of nonradioactive cysteine to the incubation media.

Despite the ability of our antibody to recognize larger molecular forms of somatostatin in tissues, we observed no evidence of such possible precursors in our continuous pulse-labeling studies. Moreover, none of the protease inhibitors such as leupeptin, antipain, and dithiodipyridine altered the results of our experiments. On the other hand, substitution of argi-

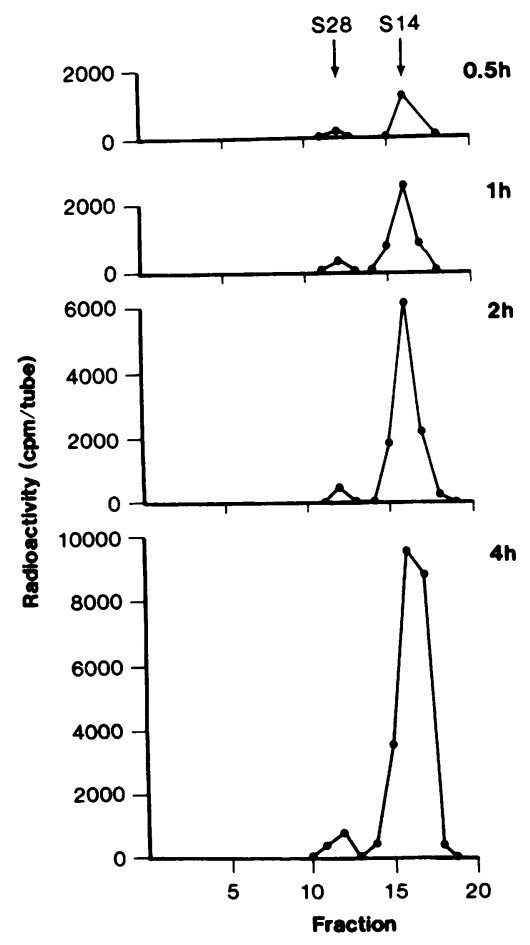

Figure 2. Elution of biosynthetic ${ }^{35} \mathrm{~S}$-labeled SLI on HPLC using a $\mu$ Bondapak C18 column $(0.8 \times 10 \mathrm{~cm})$. Fractions $(0.5 \mathrm{ml})$ were eluted isocratically with $24 \%$ acetonitrile in $0.1 \%$ TFA at a flow rate of $2 \mathrm{ml} / \mathrm{min}$. The column was calibrated by denoting the elution fractions for S28, S14, and free $\left[{ }^{35}\right.$ S $]$ cysteine (fraction 0).

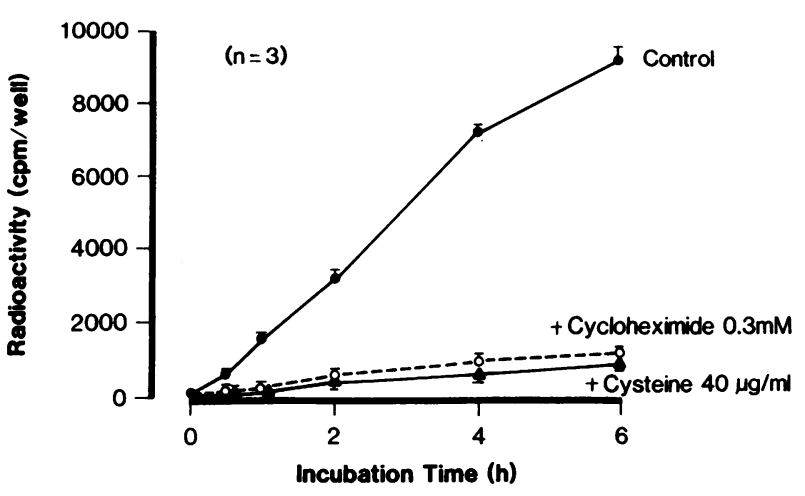

Figure 3. Time course of $\left[{ }^{35} \mathrm{~S}\right]$ cysteine incorporation into SLI in fundic $\mathrm{D}$ cells in the presence or absence (control) of cycloheximide $(0.3$ $\mathrm{mM})$ or nonradioactive cysteine $(40 \mu \mathrm{g} / \mathrm{ml})$. Results are expressed as mean $\pm \mathrm{SE}(n=3)$ of total radioactivity (cpm/well) contained within the two peaks corresponding to S28 and S14 on HPLC (see Fig. 2).

nine and lysine by their respective analogues, canavanine and thialysine, resulted in the complete inhibition of radiolabel incorporation into products corresponding to S28 and S14. When monensin, a substance known to block the intracellular transport of protein precursors at the level of the Golgi, was administered at a dose of $1 \mu \mathrm{M}$ during a 4-h labeling experiment, the incorporation of ${ }^{35}$ S $]$ cysteine into $\mathrm{S} 28$ and S14 was completely abolished, but a different affinity-adsorbable radioactive peak that eluted in the column void was obtained (Fig. 4). Although the total affinity adsorbable radioactivity was reduced to $6.0 \%$ of that without monensin, $78 \%$ of this radioactivity was immunoprecipitated with a second antisomatostatin antiserum RA823.

To explore the possible precursor-product relationship between S28 and S14, D cells that had been pulse labeled with $\left[{ }^{35} \mathrm{~S}\right]$ cysteine for $4 \mathrm{~h}$ were incubated in radioactivity-free chase medium. Under these circumstances a gradual loss of radioactivity in the peak corresponding to S14 was observed, and this loss was mirrored by a rise in S14-associated radioactivity in the medium (Figs. 5 and 6). After $6 \mathrm{~h}$ of chase-incubation,

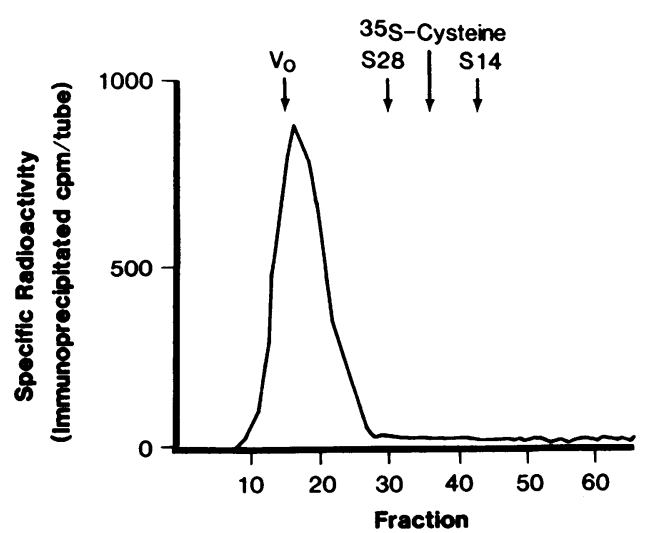

Figure 4. Chromatographic elution profile of affinity-adsorbable radioactivity in $D$ cells labeled with $\left[{ }^{35} S\right]$ cysteine for $4 \mathrm{~h}$ in the presence of monensin $(1 \mu \mathrm{M})$. The affinity eluates were applied to a Biogel P-6 column as described in Fig. 1 and each fraction was immunoprecipitated with a second somatostatin antibody as described in the methods. The values shown represent immunoprecipitated radioactivity (cpm/tube). 


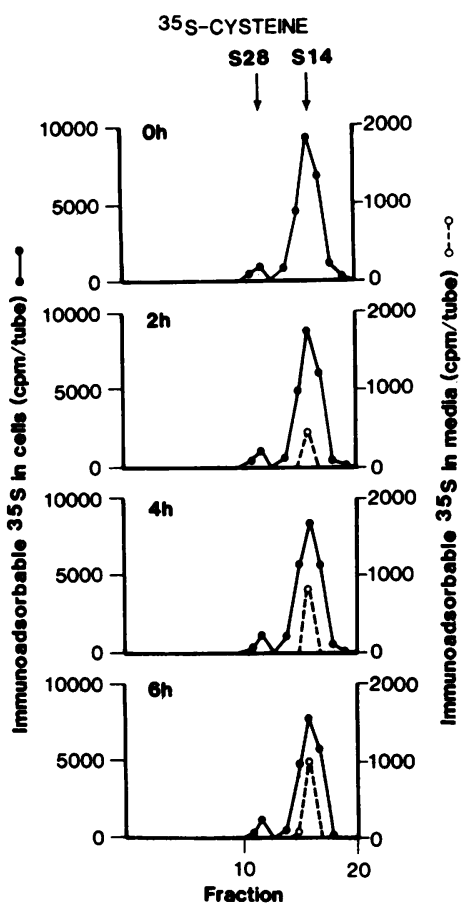

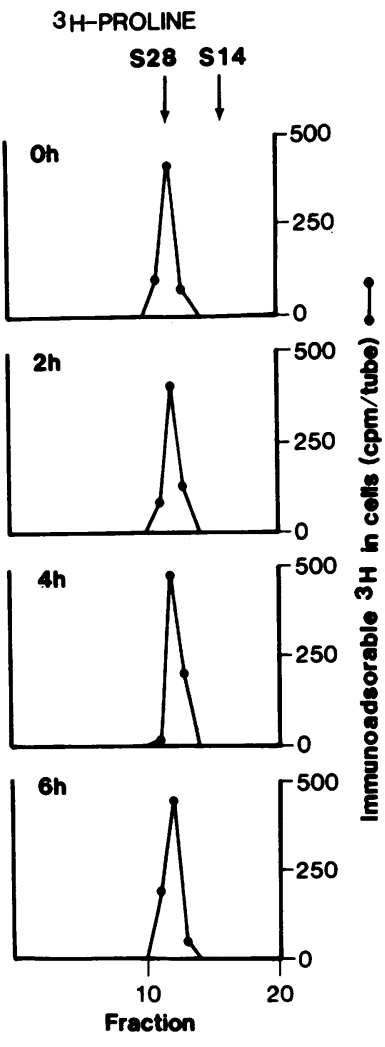

Figure 5. Chromatographic elution of affinity-adsorbable radioactivity in cell extracts and in medium from cultures pulse labeled for 4 $h$ with $\left[{ }^{35}\right.$ S $]$ cysteine, then transferred to radioactivityfree medium for the indicated periods. Affinity eluates were chromatographed using the HPLC system described in Fig. 2.

$5.2 \%$ of labeled S14 in the cells was secreted. In contrast, the amount of label incorporated into S28 did not change during the entire 6-h chase-incubation period. When a similar experiment was performed using $\left[{ }^{3} \mathrm{H}\right]$ proline in place of $\left[{ }^{35} \mathrm{~S}\right]$ cysteine, only a single radioactive peak corresponding to $S 28$ was obtained on HPLC (Fig. 7). These results are consistent with the fact that S14 has no proline residues, whereas S28 has one. During $6 \mathrm{~h}$ incubation in nonradioactive medium, the amount of radioactivity associated with $\mathrm{S} 28$ remained constant and no evidence of release into the medium was noted (Fig. 6).

In evaluating the effect of somatostatin on its own synthesis in D cells, we observed that at a concentration of $10^{-7} \mathrm{M}$ S14 significantly inhibited the incorporation of $\left[{ }^{35}\right.$ S $]$ cysteine into both $\mathrm{S} 28$ and $\mathrm{S} 14$ to $73.2 \pm 7.2 \%$ of control values (mean \pm SE, $n=3, P<0.001$ ). However, when the cells were pretreated with pertussis toxin $(200 \mathrm{ng} / \mathrm{ml})$, the inhibitory ef-

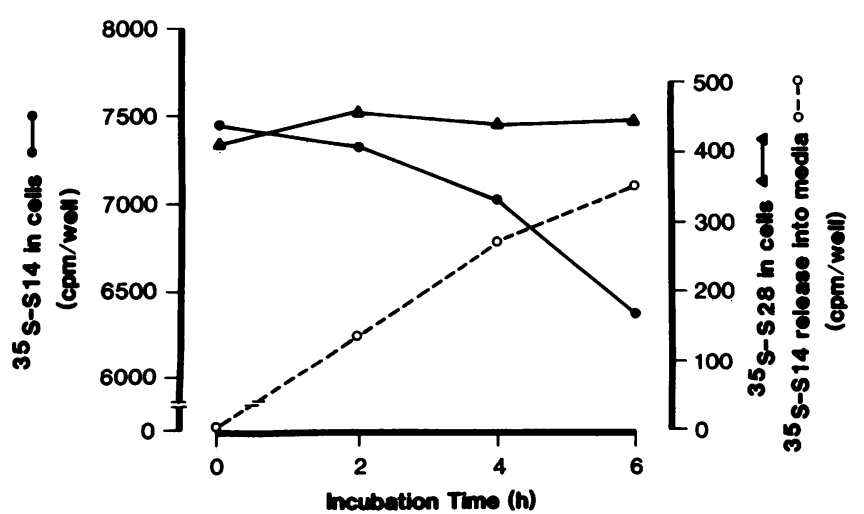

Figure 6. Release of newly synthesized somatostatin by D cells into culture media. Data from a representative experiment depicting changes in ${ }^{35}$ S-radioactivity corresponding to $S 28$ and S14 in cells and in media after chase-incubation in radioactivity-free medium are shown. Each point represents the sum of the radioactivities (cpm/ well) corresponding to S28 and S14 by HPLC as described in Fig. 2.
Figure 7. Chromatographic elution profile of affinity-adsorbable radioactivity in $\mathrm{D}$ cells pulse labeled for $4 \mathrm{~h}$ with $\left[{ }^{3} \mathrm{H}\right]$ proline then transferred to radioactivityfree medium for the indicated periods. The affinity eluates were chromatographed in the HPLC system described in Fig. 2. No affinity-adsorbable radioactivity could be detected in the media at any time point (data not shown).

fect of exogenous $\mathrm{S} 14$ on the incorporation of $\left[{ }^{35}\right.$ S $]$ cysteine into immunoreactive somatostatin was completely blocked (Fig. 8).

We further evaluated the proportion of newly synthesized somatostatin that was released in relation to the total cellular pool of the peptides. After a 4-h incubation in $\left[{ }^{35}\right.$ S $]$ cysteine, D cells were stimulated with forskolin or TPA in radioactivityfree media for $2 \mathrm{~h}$. As shown in Fig. 9, both stimulants promoted a small but significant release of SLI from the cell storage pool as measured by radioimmunoassay. In contrast, much larger fractions of the total pool of newly synthesized

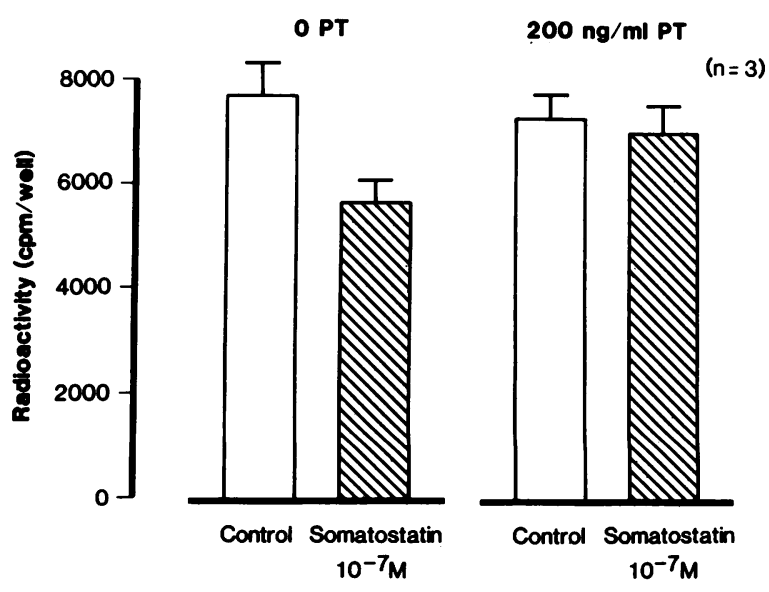

Figure 8. Autoregulation of somatostatin biosynthesis in fundic D cells. D cells with or without $4 \mathrm{~h}$ pretreatment with pertussis toxin $(200 \mathrm{ng} / \mathrm{ml})$ were labeled with $\left.{ }^{35} \mathrm{~S}\right]$ cysteine in the presence or the absence of somatostatin $\left(10^{-7} \mathrm{M}\right)$ for $4 \mathrm{~h}$. The values represent mean $\pm \operatorname{SE}(n=3)$ of total radioactivity corresponding to $S 28$ and S14 by HPLC as described in Fig. 2 (cpm/well). 

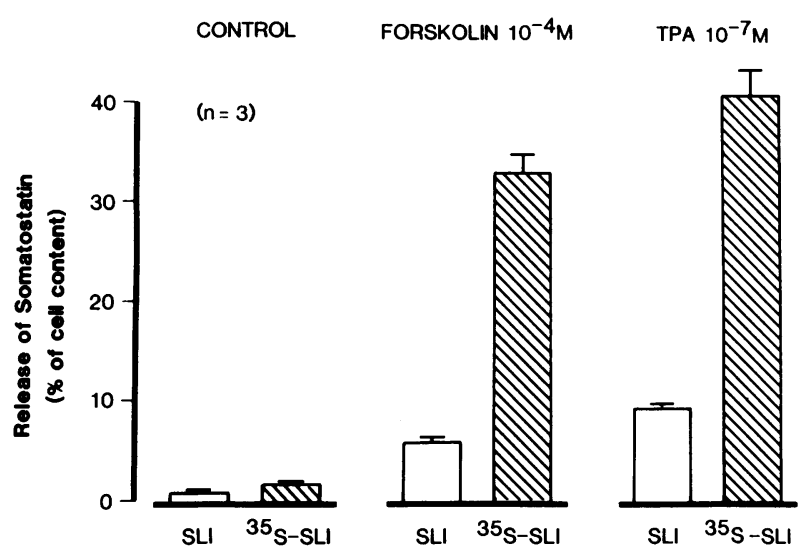

Figure 9. Effects of forskolin and TPA on the release of SLI and newly synthesized ${ }^{35} \mathrm{~S}$-labeled somatostatin. After $4 \mathrm{~h}$ pulse-incubation in ${ }^{35}$ S $]$ cysteine the cells were stimulated with forskolin $\left(10^{-4} \mathrm{M}\right)$ or TPA $\left(10^{-7} \mathrm{M}\right)$ in radioactivity-free media for $2 \mathrm{~h}$. Somatostatin both in the cells and in the media was measured by radioimmunoassay and newly synthesized ${ }^{35}$ S-labeled immunoreactivity $\left({ }^{35} \mathrm{~S}-\mathrm{SLI}\right)$ was calculated by summing the radioactivity corresponding to $\mathrm{S} 28$ and S14 on HPLC as described on Fig. 2. The release of somatostatin is expressed as percentage of total cell content of SLI or ${ }^{35} \mathrm{~S}$ $\mathrm{SLI}($ mean $\pm \mathrm{SE}, n=3$ ).

$\left[{ }^{35} \mathrm{~S}\right]$ radiolabeled somatostatin in the cells were released under the same conditions in the same cell preparations.

\section{Discussion}

Our present studies demonstrate the biosynthesis of somatostatin by canine fundic $D$ cells. The specificity of $\left[{ }^{35} S\right]$ cysteine incorporation into immunoaffinity-adsorbable S14 and S28 was confirmed by two different methods of chromatography as well as by immunoprecipitation with a second antisomatostatin antibody. The ability of cycloheximide to inhibit the incorporation of label into affinity-adsorbable material suggests that our D cells synthesized somatostatin via a standard ribosomedependent process.

Of particular interest in these studies was our initial inability to detect the synthesis of a larger precursor for S28 and S14. It is not likely that such a precursor was present but unrecognized in view of the ability of our antisera to recognize larger somatostatins in tissue extracts, as well as in biosynthesis studies in other systems (8). Furthermore, no increases in labeling of the S28 or S14 fractions were noted in our experiments after removing the D-cell cultures from radioactive medium, suggesting the absence of a sizeable labeled precursor pool. Since the structure of preprosomatostatin (15-17) clearly dictates that the immediate posttranslational product of somatostatin gene expression is larger than S28, our data suggested a rapid conversion of the precursor peptides to smaller molecular forms. Because the prosomatostatin-converting enzymes have been reported to have the characteristics of a thiol protease (18), we administered dithiopyridine, antipain, and leupeptin to our cultures with the hope of inhibiting this rapid conversion (19), but we were unsuccessful in demonstrating the larger biosynthetic precursor. In contrast, substitution of arginine and lysine with analogues effectively inhibited the generation of radiolabeled S14 and S28, presumably by inhibiting cleavage at the dibasic residues (20). However, substitution of the lysine residues with thiolysine also appeared to abolish the ability of our antisera to recognize somatostatin, since no larger precursors were visible under these circumstances either. Another possibility is that analogue substitution for the basic amino acids makes the newly synthesized peptides susceptible to rapid degradation (21). We were finally able to demonstrate the existence of an apparent somatostatin precursor by incubation of our cultures in the presence of monensin, a substance known to inhibit the transit of nascent polypeptides at the level of the Golgi apparatus (22). Others have applied a similar technique to inhibit the cellular conversion of proinsulin to insulin (23). We did not characterize the newly synthesized, putative somatostatin precursor further, thus we cannot confirm whether this compound represented the immediate translational product of the somatostatin mRNA or a processing intermediate.

Although the structure of S28 contains S14 at the carboxyl terminus, there is little direct evidence for the conversion of S28 into S14 in cells $(8-10,24)$. The identification of multiple molecular forms of carboxyl-terminal immunoreactivity for S28 ${ }_{1-12}$ in tissues suggests, at the very least, that S28 is not the only precursor for S14 (7). Our experiments demonstrated the apparent biosynthesis of both S28 and S14. Nevertheless, no data to support the derivation of S14 from S28 were obtained. Since only one somatostatin gene has been reported in mammals (15-17), our results suggest the presence of two different posttranslational processing pathways in fundic $\mathrm{D}$ cells responsible for the separate production of S28 and S14. The observation that the somatostatin precursor is a better substrate than S28 for tryptic cleavage into S14 $(25,26)$ may partially explain the selective synthesis of S14, but the mechanisms for S28 synthesis under these circumstances are unclear. It is possible that the enzymes necessary for the synthesis of S28 from its precursors, as well as those responsible for converting S28 into $\mathrm{S} 14$, are segregated into separate secretory granules and/or separate individual cells.

In preliminary studies we have observed that fundic $D$ cells contain cell surface receptors that mediate an autoinhibitory effect of somatostatin via a pertussis toxin-sensitive inhibitory guanine nucleotide binding protein that regulates adenylate cyclase activity (27). Our present studies have extended this potential effect to the regulation of somatostatin synthesis. Montminy et al. (28) have identified cyclic adenosine monophosphate responsive elements in the 5 -upstream region of the somatostatin gene, thus the inhibition of somatostatin synthesis by somatostatin through regulation of adenylate cyclase activity is not surprising. We have not yet discerned whether the autoinhibitory effect also occurs independently at the level of peptide secretion.

A novel observation made in our studies is that the fraction of radiolabeled somatostatin that was released in response to stimulation exceeded the released fraction of radioimmunoassayable somatostatin. These data suggest that the newly synthesized somatostatin represents a more readily releasable pool of peptide than does the peptide previously stored within the cell. The implication of the apparent compartmentalization of different pools of somatostatin within $\mathrm{D}$ cells requires further investigation.

\section{Acknowledgments}

This work was supportd by National Institutes of Health (NIH) grant DK-33500 and funds from the Michigan Gastrointestinal Peptide Research Center (NIH grant DK-34933). 


\section{References}

1. Yamada, T., and T. Chiba. 1987. Somatostatin. In Neuroendocrinology of the Gut. G. Makhlouf, editor. Handbook of Physiology. Section on the gastrointestinal system. American Physiological Society, Bethesda, MD. In press.

2. Chayvialle, J. A., M. Miyata, P. L. Rayford, and J. C. Thompson. 1980. Immunoreactive somatostatin and vasoactive intestinal peptide in the digestive tract of cats. Gastroenterology. 79:837-843.

3. Vinik, A. I., T. S. Gaginella, T. M. O’Dorisio, B. Shapiro, and L. Wagner. 1981. The distribution and characterization of somatostatinlike immunoreactivity in epithelial cells, submucosa, and muscle of the rat stomach and intestine. Endocrinology. 109:1921-1926.

4. Penman, E., J. A. H. Wass, M. G. Butler, E. S. Penny, J. Price, P. $\mathrm{Wu}$, and L. H. Rees. 1983. Distribution and characterization of immunoreactive somatostatin in human gastrointestinal tract. Regul. Pept. 7:53-65.

5. Soll, A. H., T. Yamada, J. Park, and L. P. Thomas. 1984. Release of somatostatin-like immunoreactivity from canine fundic mucosal cells in primary culture. Am. J. Physiol. 247:G558-566.

6. Benoit, R., P. Bohlen, N. Ling, A. Briskin, F. Esch, P. Brazeau, S. Y. Ying, and R. Guillemin. 1982. Presence of somatostatin-28(1-12) in hypothalamus and pancreas. Proc. Natl. Acad. Sci. USA. 79:917921.

7. Benoit, R., N. Ling, B. Alford, and R. Guillemin. 1982. Seven peptides derived from pro-somatostatin in rat brain. Biochem. Biophys. Res. Commun. 107:944-950.

8. Yamada, T., and S. Basinger. 1982. Biosynthesis of somatostatin-like immunoreactivity by frog retinas in vitro. J. Neurochem. 39:1539-1546.

9. Zing, H., and Y. Patel. 1982. Biosynthesis of immunoreactive somatostatin by hypothalamic neurons in culture. J. Clin. Invest. 70:1101-1109.

10. Van Itallie, C., and J. Fernstrom. 1983. In vitro studies of somatostatin-14 and somatostatin-28 biosynthesis in rat hypothalamus. Endocrinology. 113:1210-1217.

11. Yamada, T., A. H. Soll, J. Park, and J. Elashoff. 1984. Autonomic regulation of somatostatin release: studies with primary cultures of canine fundic mucosal cells. Am. J. Physiol. G567-G573.

12. Chiba, T., Y. Seino, Y. Goto, S. Kadowaki, T. Taminato, H. Abe, Y. Kato, S. Matsukura, M. Nozawa, and H. Imura. 1978. Somatostatin release from isolated perfused rat stomach. Biochem. Biophys. Res. Commun. 82:731-737.

13. Yamada, T., D. Marshak, S. Basinger, J. Walsh, J. Morley, and W. Stell. 1980. Somatostatin-like immunoreactivity in the retina. Proc. Natl. Acad. Sci. USA. 77:1691-1695.
14. Gerner, R. H., and T. Yamada. 1982. Altered neuropeptide concentrations in cerebrospinal fluid of psychiatric patients. Brain Res. 238:298-302.

15. Shen, L. P., R. Pictet, and W. Rutter. 1982. Human somatostatin I: sequence of the cDNA. Proc. Natl. Acad. Sci. USA 79:45754579.

16. Goodman, R., D. Aron, and B. Roos. 1983. Rat pre-prosomatostatin. J. Biol. Chem. 258:5570-5573.

17. Funckes, C. L., C. D. Minth, R. Deschenes, M. Magazin, M. A. Tarianine, M. Sheets, K. Collier, H. L. Weith, D. C. Aron, B. A. Roos, and J. E. Dixon. 1983. Cloning and characterization of a mRNA encoding rat preprosomatostatin. J. Biol. Chem. 258:8781-8787.

18. Fletcher, D. J., B. D. Noe, E. Bauer, and J. P. Quigley. 1980. Characterization of the conversion of a somatostatin precursor to somatostatin by islet secretory granules. Diabetes. 29:53-599.

19. Docherty, K., and D. F. Steiner. 1982. Post-translational proteolysis in polypeptide hormone biosynthesis. Annu. Rev. Physiol. 44:625-638.

20. Halban, P. A. 1982. Inhibition of proinsulin to insulin conversion in rat islets using arginine and lysine analogs. Lack of effect on rate of release of modified products. J. Biol. Chem. 257:13177-13180.

21. Halban, P. A., M. Amherdt, L. Orci, and A. E. Renold. 1984. Proinsulin modified by analogues of arginine and lysine is degraded rapidly in pancreatic B-cells. Biochem. J. 219:91-97.

22. Tartakoff, A. M. 1983. Perturbation of vesicular traffic with the carboxylic inonophore monensin. Cell. 32:1026-1028.

23. Orci, L., P. Halban, M. Amherdt, M. Ravazzola, J. D. Vassalli, and A. Perrelet. 1984. A clathrin-coated, Golgi-related compartment of the insulin secreting cell accumulates proinsulin in the presence of monensin. Cell. 39:39-47.

24. Camier, M., N. Barre, A. Morel, and P. Cohen, 1985. In vivo synthesis and processing of rat hypothalamic prosomatostatin. FEBS (Fed. Eur. Biochem. Soc.) Lett. 196:14-18.

25. Wu, P., E. Penman, D. H. Coy, and L. H. Rees. 1983. Evidence for direct production of somatostatin-14 from a larger precursor than somatostatin-28 in a phaeochromocytoma. Regul. Pept. 5:219-233.

26. Spies, J., J. Villarreal, and W. Vale. 1981. Isolation and sequence analysis of a somatostatin-like polypeptide from ovine hypothalamus. Biochemistry. 20:1982-1988.

27. Park, J., T. Chiba, and T. Yamada. 1986. Somatostatin receptors on canine fundic D-cells: evidence for autoregulation of gastric somatostatin. Gastroenterology. 90:1578. (Abstr.)

28. Montminy, M. R., K. A. Sevarino, J. A. Wagner, G. Mandel, and R. H. Goodman. 1986. Identification of a cyclic-AMP-responsive element within the rat somatostatin gene. Proc. Natl. Acad. Sci. USA. 83:6682-6686. 